\title{
Preparation of new anode of microbial fuel cell using Escherichia coli-immobilizing hydrogel
}

\author{
Dajie Xing, Hua Wang, Li Li \\ School of Biological and Food Engineering, Tianshi College, Tianjin, China \\ hunter2011@foxmail.com
}

Keywords: Microbial fuel cells; Escherichia coli; Electrically conductive hydrogel; Anode.

\begin{abstract}
Despite significant progress in recent years, microbial fuel cells (MFCs) maintain their status as one of the prime unsolved problems in clean energy technology, and their characteristics may not meet the requirements of practical application. Therefore, preparing high-performance anodes is very important for the development in this research field. In this paper, we use electrically conductive hydrogel to embed Escherichia coli and use this polymer to modify carbon paper. A new anode is fabricated, and the maximum output power, output voltage, apparent internal resistance and starting time are tested. The results show that the maximum output power of microbial fuel cell in this paper is $71.47 \mathrm{~mW} \cdot \mathrm{m}^{-2}$ and apparent resistance is $290.48 \Omega$, which are significantly better than those from conductive hydrogel-modified anode and carbon paper anode.
\end{abstract}

\section{Introduction}

Microbial fuel cells (MFCs) is a device which takes microorganisms as catalyst for catalytic oxidation of organic compounds, and transfers the chemical energy into electrical energy. MFCs has a high potential value in the field of new energy. In addition, even pollutants in sewage can be used as fuel for their production of energy. Microbial production of electrical energy is also seen as an environmentally advanced technology. However, MFCs is still in the early research stage, and its energy production capacity cannot meet the requirements of practical application.

After microorganisms are inoculated by MFCs anode chamber, they will gradually grow on the anode surface. The core of MFCs technology is the correlation between microorganisms and electrochemistry. Many factors can directly affect the performance of MFCs. With respect to the schematic of electrical production of MFCs, enriching high-density microorganisms and reducing the resistance of microorganisms transferring electrons is an effective way to improve the performance of MFCs. Embedding method is precisely the way to achieve a high density of immobilized microbial cells.

If the conductive polymer material and embedding methods are combined to embed microorganisms, the ideal MFCs anode with high density of microorganisms and articulated with electrode material can be formed. Due to polyaniline's excellent characteristics, it can be used to embed microorganisms to build a new anode material. Polyaniline has significant effect on the performance improvement in producing electricity. On the one hand, polyaniline is an organic material and is more conducive to microbial binding. On the other hand, polyaniline can directly participate in electrochemical catalytic to increase the electron transfer performance.

The study will combine polyaniline/phytic conductive hydrogel and microbial embedding technology to make MFCs anode. This method constitutes a new type of MFCs anode, which has characteristics of high density of immobilized microorganisms, high microbial activity, as well as excellent electron transfer of the inside polyaniline material.

\section{Materials and Methods}

Reagents. Aniline, AR, Tianjin Kermel Chemical Reagent Co.; Phytic acid, AR, Tianjin Guangfu Fine Chemical Research Institute; Neutral red, AR, Tianjin Jinhai Huaxing Science and Technology Development Co..

Instrument. Proton exchange membrane, Nafion 117, DuPont in America; Carbon paper, N 
series, Shanghai Daofeng Electronics Co.. Rheostat box, ZX25, Shanghai Electrical Instrument Factory; Digital multimeter, VC9806, Shenzhen Shengli Gao Electronic Technology Co..

Bacterial culture. E. coli uses LB medium and is cultured for 24 hours at $37^{\circ} \mathrm{C}$, after removing the medium and washing three times, it can be dispersed in physiological saline to dub coli suspension with approximately $20 \mathrm{mg} \cdot \mathrm{mL}^{-1}$.

Preparation of anode. Carbon paper is cut into $4 \times 4 \mathrm{~cm}$ square and is successively soaked for 24 hours with $1 \mathrm{~mol} \cdot \mathrm{L}^{-1} \mathrm{HCl}$ and $\mathrm{NaOH}$ solution. Weigh $2 \mathrm{~g}$ acrylamide, $0.4 \mathrm{~g}$ bis acrylamide and dissolve them in $2 \mathrm{~mL}$ bacterial suspension. Add phytic acid and aniline with each $1.6 \mathrm{~mL}$, then put them into ice water to cool. Then, take the solution of $1 \mathrm{~mL}$ to pour the well-fixed carbon paper surface, under nitrogen protection, add $50 \mu \mathrm{L}$ four methyl group and $1 \mathrm{~mL}$ solution of ammonium persulfate $\left(0.8 \mathrm{~g} \cdot \mathrm{mL}^{-1}\right)$, keep at $0^{\circ} \mathrm{C}$ and stand at $10 \mathrm{~min}$. Finally, rinsed the carbon paper with sterile water to remove the unfixed coli.

The comparative set is basically the same, only replace the bacterial suspension with an equal amount of deionized water.

Construction of microbial cells. Assembly dual-chamber MFCs reactor, stuck the Nafion membrane to divide the cathode and anode which are fixed to the end of the two chambers, and their compartment volume of electrolyte are $40 \mathrm{~mL}$. LB medium is added into the anode compartment. Join $10 \mathrm{~g} \cdot \mathrm{L}^{-1} \mathrm{NaHCO}_{3}, 8.5 \mathrm{~g} \cdot \mathrm{L}^{-1} \mathrm{NaH}_{2} \mathrm{PO}_{4} \cdot \mathrm{H}_{2} \mathrm{O}, 2 \mathrm{~g} \cdot \mathrm{L}^{-1}$ glucose and $80 \mu \mathrm{mol} \cdot \mathrm{L}^{-1}$ $\mathrm{NR}$ into $\mathrm{LB}$ medium as anolyte solution $(\mathrm{pH}=7)$. The composition of the cathode electrolyte solution is $0.1 \mathrm{~mol} \cdot \mathrm{L}^{-1}$ ferricyanide and $0.1 \mathrm{~mol} \cdot \mathrm{L}^{-1}$ phosphate buffer solution with $\mathrm{pH}=7$. Thereafter, access the anode compartment with $0.4 \mathrm{~mL}$ coli suspension and start MFCs. The conductive hydrogel embedded coli is taken as the anode of MFCs, join $0.4 \mathrm{~mL}$ saline in order to maintain a consistent operating conditions.

Test. MFCs performance measurement circuit is connected shown in Fig.1, by adjusting the variable resistance box to change the resistance, and the multimeter measures the voltage. Current density is calculated by $i=U /(R A)$, where, $U$ is voltage $(m V), R$ is resistance $(\Omega), A$ is the apparent area of anode material $\left(\mathrm{m}^{2}\right)$, power density is calculated by $\mathrm{P}=\mathrm{i} \times \mathrm{V}$.

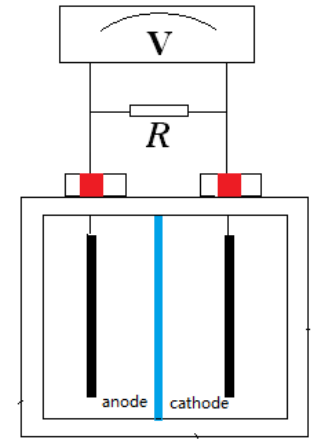

Fig. 1 Equivalent circuit of microbial fuel cell

\section{Results and Discussion}

Three kinds of MFCs anode. Polyaniline/phytic acid supplements polyacrylamide to construct conductive hydrogel, use this hydrogel to embed E. coli and fix it on carbon paper to obtain a MFCs anode. Comparison groups are: carbon paper electrode and pure carbon paper electrode. We run the three electrode under the same conditions, and test the start time, the maximum output power and the apparent resistance and other performance. Through comparative analysis, we can examine the characteristics and value of MFCs anode constructed by conductive hydrogel-embedded microorganisms.

Starting time and operating voltage. Adjusting the resistance of variable resistance box to $1000 \Omega$, the output voltage curve of MFCs can be measured (see Fig.2). It can be seen that the starting time of the two MFCs taking the conductive hydrogel entrapped coli modified carbon paper and conductive hydrogels modified carbon paper as the anode are significantly faster than the MFCs 
taking carbon paper as the anode. The output voltage of the first two battery stabilizes after running 270min and the latter substantially reaches a stable value after $350 \mathrm{~min}$. Besides, the output voltage of the first two is significantly higher than the latter. In particular, the maximum output voltage of the first MFCs reaches $274 \mathrm{mV}$, higher about $25 \%$ than the third MFCs. The growth rate and the highest maximum of output voltage is closely related with the formation of the microbial membranes on electrode surface, which indicates that the hydrogel-embedded aniline enrichment of E. coli can quickly produce electricity microorganisms.

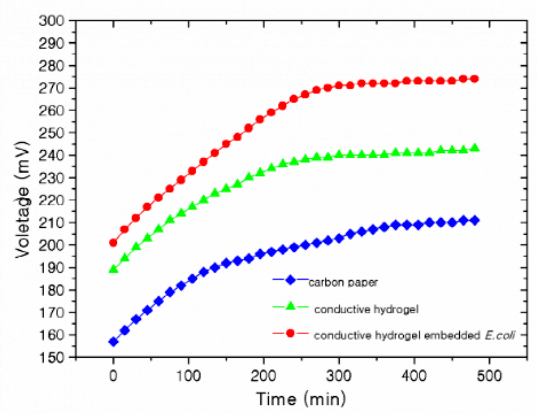

Fig.2 The time dependence o of voltage at external resistance of $10^{3} \Omega$

With comparisons between the first two MFCs, it can be seen that the maximum output voltage of the first MFCs is $30 \mathrm{mV}$ higher than that of the second MFCs, which further indicates that the amount of microorganisms in embedded way enriched more than adsorption way.

Polarization curve. Fig.3 depicts the polarization curve and power density curve of MFCs constructed by three anodes. The data in figures are measured by steady-state method. Internal resistance is calculated from the slope after linear fitting segment of the ohmic polarization in polarization curve.

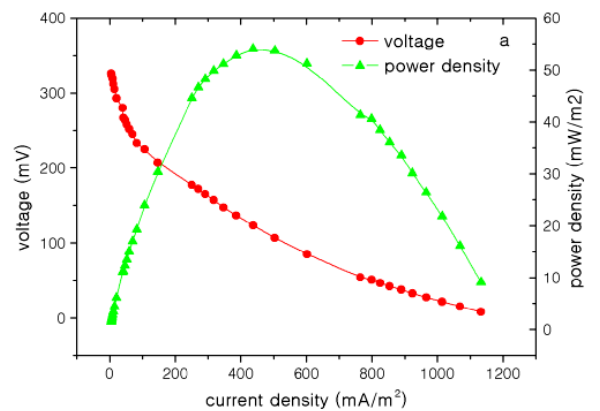

(a)

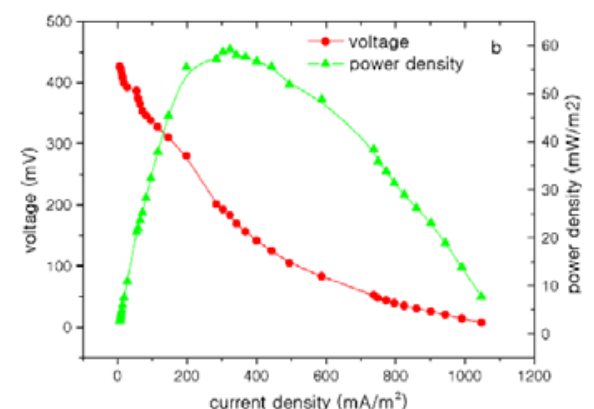

(b)

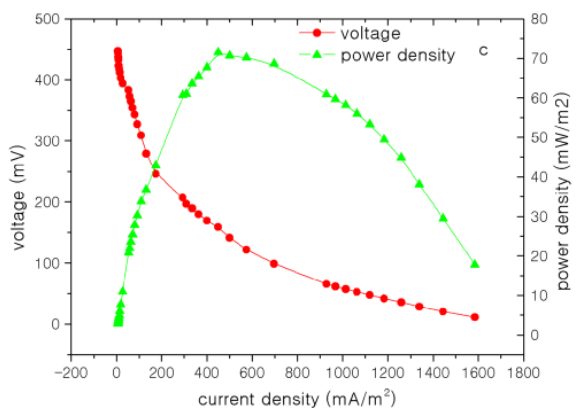

(c)

Fig. 3 Response of output voltage and power as a function of current density (polarization curve). (a) carbon paper electrode, (b) polyaniline/phytic acid/carbon paper electrode, and (c) E. coli/polyaniline/phytic acid/carbon paper electrode.

Polarization curve can be divided into three regions, the factors of power loss in each region vary. By subregional linear fit of polarization curves, we can obtain the apparent resistance within each cell (seen in Table 1). 
Table 1 Distribution of internal resistance in different parts of polarization curve

\begin{tabular}{cccc}
\hline & $\begin{array}{c}\text { Activation } \\
\text { polarizatio } \\
\text { n region/ } \Omega\end{array}$ & $\begin{array}{c}\text { Ohmic } \\
\text { polarizatio } \\
\text { n region } / \Omega\end{array}$ & $\begin{array}{c}\text { Concentration } \\
\text { polarization region }\end{array}$ \\
\hline $\begin{array}{c}\text { Carbon paper electrode } \\
\begin{array}{c}\text { Polyaniline/phytic acid/ } \\
\text { carbon paper electrode }\end{array}\end{array}$ & 1328.66 & 345.87 & 180.87 \\
$\begin{array}{c}\text { E.coli/polyaniline/phytic acid } \\
\text { / carbon paper electrode }\end{array}$ & 1219.37 & 799.86 & 224.32 \\
\hline
\end{tabular}

With apparent resistance comparison, the apparent resistance of the first two MFCs are lower than that of the third anode in this region, which shows an electrochemical reaction of polyaniline catalytic. In ohmic polarization region, the second MFCs has the highest apparent resistance with $799.86 \Omega$, which is 2 times of the third MFCs. The apparent resistance of the first MFCs in this region is only $290.48 \Omega$, which is the lowest. In the concentration polarization region, the resistance in the apparent resistance caused by the electron transfer rate dominates. The apparent resistance of the first MFCs is $115 \Omega$, which again confirms the above inference.

In view of the power density of three batteries, the first MFCs achieves the highest output power with $71.47 \mathrm{~mW} \cdot \mathrm{m}^{-2}$, and the latter two is only $59.19 \mathrm{~mW} \cdot \mathrm{m}^{-2}$ and $54.06 \mathrm{~mW} \cdot \mathrm{m}^{-2}$. Thus, the power density of the first MFCs is higher than the other two MFCs in adsorption way. Since the output power is closely related to the electron transfer efficiency, the above phenomenon shows that the new way of constructing the anode enriches more microorganisms and produces more electrons.

\section{Summary}

The anode of MFCs taking polyaniline/phytic conductive hydrogel entrapped E. as anode is fixed in a higher density of microorganisms, while reducing the resistance of microorganisms transferring electrons to the electrode and improving the efficiency of electron transferring. The MFCs taking conductive hydrogel entrapped E. as anode shows high output power density, low apparent resistance and short starting time. This new way to build MFCs anode provides a valuable electrode model to manufacture efficient microbial fuel cell.

\section{References}

[1] Allen RM, Bennetto HP. Application of microbial fuel-cells biochem. Biotechnol, 1993, 39 (1), 27-40.

[2] Rabaey K, Verstraete W. Microbial tuel cells, novel biotechnology for energy generation Trends . Biotechnol, 2005, 23 (6), 291-298.

[3] Logan BE, Hamelers B, Rozendal R, et al. Microbial Fuel Cells, Methodology and Technology . Environ. Sci. Technol. 2006, 40(17), 5181-5192.

[4] Bullen RA, Arnot TC, Lakeman JB, et al . Biofuel cells and their development • Biosens. Bioelectron, 2006, 21 (11), 2015-2045.

[5] Rabaey K, Verstraete W . Microbial fuel cells, novel biotechnology for energy generation . Trends Biotechnol. 2005, 23 (6), 291-298.

[6] Xiao M, Xu E, Chen Z. Research progress of embedding immobilized cell technology . Food Science, 2003, 24(4): 158-161.

[7] Liu C. Robust Hळ Control for Satellite Attitude Control System with Uncertainties and Additive Perturbation. International Journal of Science, 2014. 
[8] Karel SF, Libicki SB, Robertson CR. The immobilization of whole cells, Engineering principles. Chemical Engineering Science, 1985, 40(8), 13-21.

[9] Zygadto-Monikowska E, et al . Proton conducting gel polyelectrolytes based on 2-acrylamido-2-methyl-1-propanesulfonic acid (AMPSA) copolymers Part II . Hydrogels. J. Power Sources, 2006, 159, 392-398.

[10] Liu C, Shi K. Mass and mass center identification of target satellite after rendezvous and docking//Intelligent Control and Automation (WCICA), 2014 11th World Congress on. IEEE, 2014: 5802-5807.

[11] Baranitharan E, Khan MR, Prasad D, et al. Effect of biofilm formation on the performance of microbial fuel cell for the treatment of palm oil mill effluent . Bioprocess Biosyst. Eng. , 2015, 38(1), 15-24.

[12] You SJ, Ren NQ, Zhao QL, et al. Improving phosphate buffer-free cathode performance of microbial fuel cell based on biological nitrification . Biosens Bioelectron, 2009, 24 (12), 3698-3701. 